\title{
Individual and group-based learning from complex cognitive tasks: Effects on retention and transfer efficiency
}

Citation for published version (APA):

Kirschner, F., Paas, F., \& Kirschner, P. A. (2009). Individual and group-based learning from complex cognitive tasks: Effects on retention and transfer efficiency. Computers in Human Behavior, 25(2), 306-314.

https://doi.org/10.1016/j.chb.2008.12.008

DOI:

10.1016/j.chb.2008.12.008

Document status and date:

Published: 01/03/2009

Document Version:

Early version, also known as pre-print

Please check the document version of this publication:

- A submitted manuscript is the version of the article upon submission and before peer-review. There can be important differences between the submitted version and the official published version of record. People interested in the research are advised to contact the author for the final version of the publication, or visit the DOI to the publisher's website.

- The final author version and the galley proof are versions of the publication after peer review.

- The final published version features the final layout of the paper including the volume, issue and page numbers.

Link to publication

\section{General rights}

Copyright and moral rights for the publications made accessible in the public portal are retained by the authors and/or other copyright owners and it is a condition of accessing publications that users recognise and abide by the legal requirements associated with these rights.

- Users may download and print one copy of any publication from the public portal for the purpose of private study or research.

- You may not further distribute the material or use it for any profit-making activity or commercial gain

- You may freely distribute the URL identifying the publication in the public portal.

If the publication is distributed under the terms of Article 25fa of the Dutch Copyright Act, indicated by the "Taverne" license above, please follow below link for the End User Agreement:

https://www.ou.nl/taverne-agreement

Take down policy

If you believe that this document breaches copyright please contact us at:

pure-support@ou.nl

providing details and we will investigate your claim.

Downloaded from https://research.ou.nl/ on date: 26 Apr. 2023 
Running head: INDIVIDUAL AND GROUP-BASED LEARNING

This is a pre-print of:

Kirschner, F., Paas, F., \& Kirschner, P. (2009). Individual and group-based learning from complex cognitive tasks: Effects on retention and transfer efficiency. Computers in Human Behavior, 25, 306314.

Copyright Elsevier, available online at: http://www.elsevier.com/wps/find/journaldescription.cws home/759/description\#description

Individual and Group-Based Learning from Complex Cognitive Tasks: Effects on Retention and Transfer Efficiency

Femke Kirschner ${ }^{1}$, Fred Paas ${ }^{1,2}$, and Paul A. Kirschner ${ }^{1,3}$

${ }^{1}$ Educational Technology Expertise Center, Open University of the Netherlands

${ }^{2}$ Institute of Psychology, Erasmus University Rotterdam

${ }^{3}$ Research Centre Learning in Interaction, Utrecht University

Correspondence concerning this article should be addressed to Femke Kirschner, Open University of the Netherlands, Educational Technology Expertise Center, P.O. Box 2960, 6401 DL, Heerlen, The Netherlands. T: +31 45 5762878; F: +31 45 5762800; E:

femke.kirschner@ou.nl 


\section{Abstract}

The effects of individual versus group learning (in triads) on efficiency of retention and transfer test performance in the domain of biology (heredity) among 70 high-school students were investigated. Applying cognitive load theory, the limitations of the working memory capacity at the individual level were considered an important reason to assign complex learning tasks to groups rather than to individuals. It was hypothesized that groups will have more processing capacity available for relating the information elements to each other and by doing so for constructing higher quality cognitive schemata than individuals if the high cognitive load imposed by complex learning tasks could be shared among group members. In contrast, it was expected that individuals who learn from carrying out the same complex tasks would need all available processing capacity for remembering the interrelated information elements, and, consequently, would not be able to allocate resources to working with them. This interaction hypothesis was confirmed by the data on efficiency of retention and transfer test performance; there was a favorable relationship between mental effort and retention test performance for the individual learners as opposed to a favorable relationship between transfer test performance and mental effort for the students who learned in groups.

Keywords: Collaborative learning, Individual learning, Learning efficiency, Task complexity, Transfer performance, Cognitive Load 
Individual and Group-Based Learning from Complex Cognitive Tasks: Effects on Retention and Transfer Efficiency

Collaborative learning models are based on the premise that certain types of learning are best achieved interactively rather than through a one-way transmission process (Johnston, James, Lye, \& McDonald, 2000; Littleton \& Häkkinen, 1999; Slavin, 1983, 1995; Veerman, 2000; Veerman \& Veldhuis-Diermanse, 2001; Weigel, 2002). Although collaborative learning is emerging as a promising educational approach, research on its effects on learning has been highly inconclusive (Kester \& Paas, 2005). We believe that these inconclusive results have, among other things, been caused by a lack of attention to the structures constituting human cognitive architecture (Sweller, 1988; Sweller \& Sweller, 2006; Sweller, Van Merriënboer, \& Paas, 1998) when designing collaborative learning environments.

Research stressing the potential of collaborative learning shows that collaborative learning environments can stimulate and/or enable learners to engage in activities that are valuable for learning. Activities such as self-directed learning, negotiating meaning (Beers, Boshuizen, \& Kirschner, 2007; Kirschner, Beers, Boshuizen, \& Gijselaers, 2008), verbalizing explanations, justifications and reflections, giving mutual support (Van Boxtel, Van der Linden, \& Kanselaar, 2000), and developing arguments about complex problems or propositions (Munneke, Andriessen, Kanselaar, \& Kirschner, 2007) have been found to facilitate the learning process. Collaborative learning has also been shown to help learners retain the learned information longer (Morgan, Whorton, \& Gunsalus, 2000) and to foster their higher-order skills more than in more traditional lecture-based learning environments (Sloffer, Dueber, \& Duffy, 1999). It is important to note that these positive results were found in studies that implemented 'extra' measures to ensure that participants engage in effective collaboration, primarily using 
highly constrained and scripted collaborative learning environments (Dillenbourg, 2002; Fischer, Bruhn, Gräsel, \& Mandl, 1999, 2002; Kollar, Fischer, \& Hesse, 2006); learning environments in which communication and coordination were bound to strict rules and formats to make sure that learners knew what they had to do, how they were supposed to do it, with whom they had to work and/or what they had to communicate about. Studies using less scripted or constrained environments show mixed and even negative findings regarding both learning process (Gregor \& Cuskelly 1994; Hallet \& Cummings, 1997; Heath, 1998; Mason, 1991), and group forming and group dynamics (Hiltz, 1998; Hobaugh, 1997; Hughes \& Hewson 1998; Taha \& Caldwell, 1993).

It has become clear that placing learners in a group and assigning them a task does not guarantee that they will work together, engage in effective collaborative learning processes, and show positive learning outcomes (Soller, 2001). However a controlled collaborative learning environment is also not a guarantee for success. There is research on collaborative learning showing that, even when learners were engaged in collaborative learning in which groups were effectively formed and cognitive learning processes were successfully supported, beneficial effects were not always found (Beers, 2005; De Westelinck, De Craene, \& Kirschner, 2005; Makitalo, Weinberger, Häkkinen, Järvelä, \& Fischer, 2005; Van Bruggen, Kirschner, \& Jochems, 2000; Van Drie, Van Boxtel, Jaspers, \& Kanselaar, 2005).

Inconclusive results have also been found in studies comparing individual performance to group performance when subjects had to recall as many information elements as possible after studying them for a certain amount of time. In these scripted and constrained environments, groups outperformed individuals in the amount of items recalled. However, if group performance was compared to the sum of individual scores (i.e., the nominal score), in most cases group 
performance was inferior to that of the nominal group, meaning that when working together in a group to recall information, individuals recalled less than when they worked alone. The results of these recall studies suggest that the collaboration process is detrimental for group-member performance even though the environment was constrained and communication and coordination were bound to rules and kept to a minimum (Andersson \& Rönnberg, 1995; Meudell, Hitch, \& Kirby, 1992; Weldon \& Bellinger, 1997).

Different results were found when the tasks used were problem-solving tasks instead of recall tasks. When learners had to work with the information elements, relate them to each other, and by doing so find the solution to a problem, groups again outperformed individuals but they also outperformed the nominal group (Laughlin, Bonner, \& Miner, 2002; Laughlin, Hatch, Silver, \& Boh, 2006). This time, participating in a group facilitated the performance of the individual group member. The type of the task seems to be an important factor in determining whether collaboration is beneficial or not.

Recall tasks in which remembering is the main goal can be seen as relatively simple tasks, whereas problem solving tasks in which working with information is most important can be seen as relative complex tasks. The research in which individuals and groups are compared regarding their recall or problem-solving performance implies that individual learning is superior to group learning for relatively simple recall tasks, and that group learning is superior to individual learning for relatively complex problem-solving tasks. A possible explanation for this can be found in cognitive load theory (CLT: Paas, Renkl, \& Sweller, 2003, 2004). CLT is mainly concerned with individual learning from complex cognitive tasks. It assumes that individuals cannot process an unlimited number of information elements in their working memory (WM). According to Cowan (2001), WM is limited to 4 plus or minus 1 information element if the 
elements are interrelated and, consequently, have to be combined, contrasted or worked on for understanding to take place. According to CLT, a task can impose three kinds of load on an individual: intrinsic load, extraneous or ineffective load, and germane or effective load (Sweller et al., 1998). Intrinsic cognitive load caused by element interactivity is determined by a combination of the number of information elements and the interaction between the elements that have to be related to each other (the intrinsic nature of the material) and the expertise of the learners. Because this load is intrinsic to the task, it is assumed that it cannot be directly influenced by instructional designers. Extraneous cognitive load is the load resulting from poorly designed instruction that does not contribute to learning. An example of this is the cognitive load caused by the searching for relevant information during unguided discovery learning in problemsolving tasks (Kirschner, Sweller, \& Clark, 2006; Sweller, Kirschner, \& Clark, 2007). Germane cognitive load is the load related to the instruction that contributes to effective learning. Both extraneous and germane load are under the direct control of instructional designers. Because intrinsic load, extraneous load, and germane load are additive, from a cognitive load perspective, it is important to realize that the total cognitive load associated with an instructional design - the sum of the three loads - should stay within working memory limits (Paas, Tuovinen, Tabbers, \& Van Gerven, 2003).

Applying the principles of CLT, this study considers groups as information processing systems consisting of multiple (limited) WMs which can create a collective working space. From this theoretical point of view, multiple collaborating WMs always provide more processing capacity, but whether this capacity can be used effectively depends on the type of task. It can be argued that a group has more effectively available processing capacity than an individual information processing system for tasks in which the relevant information needs to be shared 
among working memories for learning to commence. In a group, the cognitive load imposed by a task can be shared among group members, and by doing so free-up WM capacity at the individual level that can be used to deal with more complex problems and construct higher quality cognitive schemata compared to an individual working alone. Therefore, the limitations of the WM-capacity at the individual level can be argued to be an important reason to assign complex learning tasks to groups rather than to individuals.

However, creating a collective working space is only possible if the relevant knowledge held by each individual group member is communicated and coordinated within the group (Salas, Simms, \& Burke, 2005). Communication leads to shared cognition and the construction of shared mental models, which have been identified as key aspects of collaboration (Barron, 2003). Through social interaction within the team, a collective knowledge structure is formed, which is conditional for team success. Research shows that mutually shared cognition is the result of knowledge building in socio-cognitive processes and is directly linked to team effectiveness (Van Den Bossche, Gijselaers, Segers, \& Kirschner, 2006). Communication is especially important when the information needed to successfully solve a problem is distributed among group members so that all members possess different but crucial information. Research on the hidden profile paradigm has shown that in complex decision making, collaborators do not effectively share the 'unshared' information (i.e., information that is only available to a group member). In such complex tasks, groups do not work well (Whyte, 1991). It is therefore important that when performing complex tasks that learners are stimulated to exchange knowledge and information. Making learners dependent on each other either for successfully carrying out and completing a task (i.e., task/goal interdependence) or for exchanging resources (i.e., positive resource interdependence) are ways of doing this. Task or goal interdependence 
refers to the interconnecting subtasks, such that the performance of one piece of work on a task or project depends on the completion of other pieces (Langfred, 2000). It involves members of a team depending on one another to accomplish both individual and team goals (Campion, Medsker, \& Higgs, 1993). Wageman (1995) determined that reducing interdependency by dividing tasks into independent subtasks negatively influences team performance. Positive resource interdependence holds that learners working within a group receive only a part of the resources, information, or materials necessary for the task to be completed and, thus, that they need and access the other necessary resources through their partner or partners (Johnson, Johnson, \& Stanne, 2001; Ortiz, Johnson, \& Johnson, 1996). Research on resource interdependence shows that when learners are allocated only part of the resources necessary to achieve specific goals, effective information transmission, and positive interaction and cooperation is favored and performance enhanced (Buchs, Butera, \& Mugny, 2004).

As shown, structure and control of knowledge communication and coordination are very important for collaborative learning environments to be effective. The beneficial effect of being able to share the cognitive load within a group could be annulled by the costs of communication and coordination between the group members, the so called cognitive and social transaction costs. This concept of transaction costs is more and more used in the field of learning and especially collaborative or cooperative learning (i.e., learning in groups; Ciborra \& Olson, 1988; Yamane, 1996). It originates from the field of economics, and in economics concerns those costs, other than the money price, that are incurred in trading goods or services. Within a collaborative or cooperative learning environment these transaction costs are "the costs of setting up, enforcing, and maintaining the reciprocal obligations, or contracts, that keep the members of a team together [and]...represent the "overhead" of the team...linked to the resources (time, skills, 
etc.) employed to allow a work team to produce more than the sum of its parts" (Ciborra \& Olson, p. 95). In our situation, they refer to the specific cognitive load that has to be taken into account when learners are communicating with other learners and coordinating both the carrying out of the task and the communication between each other.

When communicating and exchanging information learners are forced to come up with and agree upon a common solution by combining and integrating their individual ideas into a shared and collective one. Group coordination manages the interdependencies between group members so that every group member knows exactly which activities other members are carrying out, or will carry out, in order to effectively determine what one's own activities at the moment and in the future should entail (for a general discussion about coordination theory see Malone \& Crowston, 1990). Group coordination has to happen at both the group level (e.g., allocating resources and defining workflow, see Ellis, Gibbs, \& Rein, 1991) and the task level (e.g., a shared editor use requires group members to know exactly where others are typing, see Dourish \& Bellotti, 1992; Gutwin, 1997). Because CLT has exclusively focused on individual learners performing an individual task, the cognitive load associated with initiating and maintaining communication and coordination - the transaction costs - have not received specific attention. However, collaborative learning environments can only be effectively designed if those costs are taken into account. The transaction costs can be argued as imposing intrinsic, germane, or extraneous cognitive load on learners. Intrinsic load is imposed when communication and coordination are inherent to a collaborative learning situation and/or environment, one cannot exist without the other. Germane load is imposed when the transaction costs are effective for learning because they foster shared understanding, trust, mutual performance monitoring, common ground, argumentation, coordination, and positive cognitive conflicts (Leitão, 2000; 
Mercer, 1996; Munneke et al., 2007; Salas et al., 2005; Savery \& Duffy, 1995) which have been shown to facilitate the learning process. Extraneous load is imposed when the transaction costs are ineffective for learning because it fosters errors, conflicts, unnecessary duplication, etc. (Bernard \& Lundgren-Cayrol, 2001; Webb \& Palincsar, 1996). .Especially the extraneous or ineffective cognitive load should be minimized for collaborative learning to be effective. If these costs are not controlled and minimized, the freed-up WM-capacity at the individual level could be used for non-essential or non-learning related communication such as discussing who is going to fill in the answer, telling others what you bought yesterday, and fighting about the goal of the task, instead of constructing high quality cognitive schemata. The advantage of being able to share the cognitive load that a complex task causes could be annulled by too high transaction costs.

Taking both the complexity of the task and the transaction costs into account, a prerequisite for group-based learning being more effective than individual learning would be that the demands involved in carrying out the task alone exceed the sum of the cognitive resources that a single individual can supply and the resources needed to deal with the ineffective social transaction costs of communication and coordination of the knowledge between the group members. This is almost always the case in collaborative learning situations where the task that the learners must carry out demands simultaneous processing of the information that cannot be offloaded by the individual at any one time. In those situations, group members are expected to be more able to apply the knowledge and skills acquired in carrying out a cognitively complex learning task to tasks that differ from the ones trained, as indicated by more efficient and effective transfer performance. In contrast, individuals carrying out the same complex tasks do not have the possibility to distribute the load and, therefore, have less WM-capacity left to work 
with the interrelated information elements. Although the transaction costs do not exist here, the risk of the individual becoming cognitively overloaded is quite high. Consequently, they are minimally expected to be able to only focus on remembering the interrelated elements, as indicated by more efficient retention performance.

A drawback of many of the studies comparing individual learning with group learning has to do with the fact that the claims about the effects on learning are often only indirectly tested by measuring acquired skills, performance, and/or group processes in the learning phase (e.g., number of contributions, moves, types of contributions, etc.), and not directly by measures of actual learning performance. One can learn from complex cognitive tasks or can carry out complex cognitive tasks, through which it is assumed or hoped that learning also occurs. This need not be the case. Some criticism of problem based learning is based upon findings that while the problems are successfully solved, the learners do not effectively learn from working together (Kirschner et al., 2006; Sweller et al., 2007). In addition, because of indirect testing, measures are often a determination of the quality of the group product or group process rather than of individual learning. Cognitive load theory takes these issues into account by incorporating specific claims concerning the role of cognitive load within an instructional context and its relation to individual learning (for an overview see Paas, Tuovinen, et al., 2003). Most importantly, it recognizes that a meaningful interpretation of a certain level of cognitive load can only be given in the context of its associated performance level, and vice versa. For instance, a performance score on a test does not provide any information about the cognitive costs at which this performance was attained. Therefore, taking both measures into account gives a better indication of the quality of the cognitive schemata participants have acquired than performance scores alone. This insight has led Paas and Van Merriënboer (1993; see also Tuovinen \& Paas, 
2004; Van Gog \& Paas, 2008) to develop a computational approach for examining the observed relation between measures of test performance and measures of mental effort invested in completing the test. This approach enables cognitive load theorists and instructional designers to calculate and compare the efficiency of instructional conditions: High task performance associated with low mental effort is termed high performance efficiency, whereas low task performance with high mental effort is termed low performance efficiency. The value of the approach has been shown by revealing differential effects of varying instructional methods that would have been unnoticed with conventional performance measures (for an overview see Paas, Tuovinen, et al., 2003).

In this study, it is hypothesized that when performing complex tasks group members will be able to collaborate with one another in a fashion that reduces the high intrinsic cognitive load and therefore will be able to develop higher quality schemata than learners working individually. Higher quality schemata would allow those working in groups to attain higher performance on transfer tasks with less investment of mental effort than individual learners. By contrast, it was expected that those learning from carrying out the same complex tasks individually would need all of their processing capacity for remembering the interrelated information elements, and consequently, would not be able to allocate resources to working with and applying them. This would allow those working individually to attain higher performance on retention tasks with less investment of mental effort than group members. Group members will be able to solve a problem by collaboratively combining the information elements that are distributed across the multiple working memories in the group. Consequently, there will be no need for group members to remember all information elements. 


\section{Participants}

Participants where 70 fourth year Dutch high school students (38 boys and 32 girls) with an average age of 15.4 years $(\mathrm{SD}=0.7)$ who participated in the experiment as part of a biology course. Prior knowledge concerning biology-related topics was assumed to be approximately equal for all participants, because they had all followed the same courses using the same instructional materials in the preceding years. To assure comparability, they were randomly assigned to the different experimental conditions (i.e., individual vs. triadic group). They did not receive any financial or academic compensation for participation, but six tickets to an amusement park were raffled off.

\section{Materials}

All materials used in this experiment were in a domain of biology concerned with heredity, specifically the transfer of both genotypic and phenotypic biological characteristics from parents to their offspring through genes which carry biological information (e.g., eye color in humans, fur length in dogs, leaf shape in plants). The following topics are important when introducing hereditary characteristics: genes, genotype and phenotype of an organism, homozygosity or heterozygosity of an organism's dominant or recessive genes, and genealogical tree. In this domain, a general introduction and an instruction on how to solve inheritance problems, three problem solving tasks, and six transfer tasks were designed. All tasks (i.e., learning and test), as well as the introduction and instruction where paper based, however, a computer was used solely for time management.

The introduction. The general introduction and instruction on solving heredity problems discussed the relevant heredity characteristics, the basic terminology, the rules and theory underlying heredity, and the combination of this general instruction in a worked out example of 
how to solve heredity problems. The worked out example combined terminology, characteristics, rules, and theory.

Learning tasks. Learners were required to use the information and worked out example presented in the introduction to carry out three similar problem-solving tasks. These problemsolving tasks required learners to combine a number of necessary information elements to give a correct answer to two questions concerning the proportion of possible genotypes of the offspring. Each piece of information was relevant but insufficient by itself for solving the problem, but when combined with the other information the problem could be solved. In the domain of heredity this, for instance, could mean that information element 1 is eye color of the mother: blue; information element 2 is eye color of the father: brown; and information element 3 is the dominance of brown eyes over blue eyes. Each element gives a certain amount of information, but to answer the question as to what the eye color of the offspring will be, the learner will have to combine all three pieces of information. All learners assigned to the individual or group condition received the learning tasks as a booklet. While learners in the individual condition received all information elements necessary for performing the task, these information elements were distributed in the group in such a way that every triadic group member only received one third of the information elements necessary for performing the task.

Test tasks. Three retention tasks and three transfer tasks were designed to determine how much was learnt. The first three tasks consisted of problems that were almost identical to the learning tasks that the learners received during the learning phase. Although the tasks differed on the organism used (e.g., a fruit fly was used instead of a guinea pig), the process of solving the problem was identical. To solve these problems, learners only had to remember the worked out example that they had received in the introduction and remember what they practiced in the 
learning phase. The other three tasks consisted of problems that differed structurally from the training tasks. Although the same characteristics, basic terminology, rules, and underlying heredity-theory had to be used, the way it had to be used was structurally different from the learning tasks. The topics used in the transfer tasks were the genealogical tree, X-chromosome linked inheritance, and dihybrid crossings. To solve these problems, learners had to flexibly use the knowledge of heredity that they had acquired in the learning phase. All learners received the transfer tasks in a booklet.

Instruction. All learners received two non-content related instructions, one immediately before the learning tasks, and one before the transfer tasks. These instructions included the procedure, rules, and use of computer, pen, and paper when working on the learning or transfer tasks. The procedure in the learning phase was different for learners in the different conditions. Learners in the individual condition first had to read all information elements thoroughly, then had to individually read the questions, and finally had to try to answer the questions as correctly and quickly as possible using all information elements. Learners in the group condition did not have to read all information elements, but rather only the ones that where allotted to them, then had to read the questions, and finally had to answer the questions together as correctly and quickly as possible using their own as well as each other's allotted information elements. Every group member received one third of the total number of information elements necessary for answering the heredity questions on paper. No information elements were redundant and the number of information elements was the same for all group members. For all learners in all conditions, the rules on using pen and paper while solving the problem were the same, namely that its use was prohibited. It was important that all information elements were held in working memory and could not be offloaded onto the booklet. For learners in the group condition, it was 
stressed that working together was necessary for solving the problem. Face-to-face communication was very important here, but transaction costs had to be held to a minimum so as not to cause an overload from an extraneous load that is ineffective for learning. Therefore, learners were only permitted to communicate about task related topics, coordination tasks concerning computer use were assigned to group members at the beginning of the learning phase, and instructions on when to do what were written down before and after each task. Also, tasks were designed in such a way that information elements in the group condition were divided into three parts so that every group member received only one part of the information required to solve the problem. This forced distribution of information elements, or knowledge, and limited the coordination costs for the group members, because they did not have to do this division themselves. Learners in both conditions had a fixed amount of time that could be spent working on the task (i.e., 10 minutes on the first task and 12 on the second and third tasks).

The instruction preceding the transfer tasks was the same for all participants and almost identical to the instructions in the individual condition during the learning phase. Again, they first had to read all information elements thoroughly, then read the questions, and finally try to answer the questions as correctly and quickly as possible using all information elements. But this time, they had to use pen and paper to write down exactly what they were doing and there was a minimum time of 2 and a maximum time of 10 minutes for solving each task.

Computer. The computer was solely used for time registration and time management. At the beginning of a task, when the learners started to read the first information elements, it was possible to click a start button. To register their time on task, they had to type their answer to a question and then click the 'save-button' on the screen with the mouse. After this, if still within the fixed amount of time given for a task, it was possible to change the answer and click the 
save-button again. The last answer saved was used to determine both time on task and correctness of response. The time management function of the computer consisted of a countdown in the learning phase, showing the participants the amount of time remaining for answering the questions or showing them - after they typed their answer - how much time was still available for thinking or talking about the task. In the test phase, the computer only showed the time remaining to complete a task. Working individually on learning or test tasks each learner had a private computer at his/her disposal. This was different in the group condition, where one of the group members was assigned the responsibility of typing in the final answer and clicking the save-button on the one computer per group. Although the group only used one computer, all group members were able to look at the computer screen to watch the count-down. The computers were not used for exchanging information.

Cognitive-load measurement. After each task in the learning and test phase, the participants were required to indicate how much effort they had invested in answering the questions by rating this on a 9-point cognitive-load rating scale (Paas, 1992; see also Paas \& Van Merriënboer, 1994b), ranging from 'very very low effort' to 'very very high effort'.

Performance measurement. The retention test consisted of three complex problemsolving tasks in the domain of heredity, that were almost identical to the tasks received in the learning phase. Each task consisted of a number of information elements that had to be combined to solve the problem. Solving the problem meant answering four questions related to the genotypes, phenotypes, and proportion of both in a certain (fruit fly) family. A participant received one point for giving a correct answer to each of the four questions, thus the minimum score for a task was 0 points and the maximum 4 points. The maximum retention test score was 12 points. 
The transfer test consisted of three complex problem-solving tasks in the domain of heredity that differed from the learning tasks on certain structural features. Each task consisted of a number of information elements that had to be combined to solve the problem, which meant answering two or three questions related to the genotypes of a certain family (e.g., dog, chicken, fruit fly). One point could be earned for a correct answer to every question, thus the minimum score for the transfer tasks was 0 points and the maximum score was 2 or 3 points depending on the number of questions in a task. The maximum transfer test score was 7 points. For the statistical analysis, the performance scores on retention and transfer were transformed into proportions. In other words, a participant's score on the three retention tasks and the three transfer tasks were divided by the maximum score of the retention test (i.e., 12) and the transfer test (i.e., 7), respectively.

Efficiency measurement. Performance efficiency was calculated for the retention and transfer tests using Paas and van Merriënboer's (1993; see Van Gog \& Paas, 2008) computational approach by standardizing each of the participants' scores for retention-test and transfer-test performance, and mental effort invested in the retention and transfer tests respectively. For this purpose, the grand mean was subtracted from each score and the result was divided by the overall standard deviation, which yielded $z$-scores for effort $(R)$ and performance $(P)$. Finally, a performance efficiency score, $E$, was computed for each participant using the formula: $E=\left[(P-R) / 2^{1 / 2}\right]$. High efficiency was indicated by a relatively high test performance in combination with a relatively low mental-effort rating. In contrast, low efficiency was indicated by a relatively low test performance in combination with a relatively high mental-effort rating. 


\section{Design and Procedure}

Participants were randomly assigned to the individual or group learning condition in such a way that 16 participants worked individually on the three learning tasks and 54 participants worked in 3-person groups (i.e., triads). All participants had to individually study a general introduction to heredity concepts and problems. They received this introduction on paper and had to hand it in after 20 minutes. The participants were then randomly assigned to the individual or group condition to work on the first learning task which took 10 minutes. After the task, each learner had to rate the amount of invested mental effort on the 9-point rating scale. Next, they worked on the second learning task for which they had 12 minutes. After this task, they had to again rate the amount of mental effort invested. Finally, they worked on the third learning task, also for 12 minutes, and rated the amount of invested mental effort. After this learning phase, participants in the group condition were set apart and all (i.e., individuals and groups) had 1 hour to individually solve three retention problems requiring them to individually apply the newly learned principles in familiar situations, and three transfer problems requiring them to use the principles in new, unfamiliar situations. During the test phase, the amount of invested mental effort was measured after each transfer task using the same cognitive load scale used in the learning phase.

\section{Results}

\section{Learning Phase}

Table 1 shows the means and standard deviations of the dependent variables in the learning phase as a function of learning condition. A significance level of .05 was used for all analyses. Cohen's $d$ was used as a measure of effect size, where $d$-values of .20, .50, and .80, correspond to small, medium, and large effects respectively (Cohen, 1988). Individual mental- 
effort scores and individual performance-scores are an average of the scores of the three learning tasks. For the group mental-effort scores, an intermediate calculation was necessary. The three group member scores were averaged into one group score. These group scores were then used to calculate the average mental effort of the three tasks. For the performance score, this intermediate calculation was not necessary because groups gave a group answer to the questions.

\section{****INSERT TABLE 1 ABOUT HERE****}

An independent sample $t$-test revealed that group members invested significantly less mental effort than participants who learned individually, $t(32)=2.03, p<.05$ (one-tailed), $d=0.74$. An independent sample $t$-test revealed that group members performed significantly better on the learning tasks than participants who learned individually, $t(32)=-3.01, p<.05$ (one-tailed), $d=1.15$. There was no significant difference between group members and individuals on the amount of time invested in solving the problem, $t(32)=-.22, n s$. Test Phase

A 2 (learning condition: individual vs. group) x 2 (type of test: retention vs. transfer) ANOVA with repeated measures on the latter factor was used to analyze the data obtained during the test phase. For all analyses, the first factor - learning condition - was a betweensubjects factor, and type of test was a within-subjects factor. Means and standard deviations per condition for the dependent variables - performance, mental effort, efficiency, and time for both retention and transfer test - are provided in Table 1. Cohen's $f^{2}$ statistic was used as an effect size index, where $f^{2}$ values of $.02, .15$, and .35 correspond to small, medium, and large effects respectively (Cohen, 1988). Mental effort scores and performance scores of the learners assigned to the individual condition in the learning phase are an average of the scores of the three retention tasks and three transfer tasks. For learners assigned to group condition in the learning 
phase, an intermediate calculation was necessary. The group member scores were averaged into one group-score. These group scores were used to calculate the average of the three retention tasks and three transfer tasks. With regard to efficiency, the ANOVA revealed no main effects of learning condition, $F(1,32)<1$, $n s$, and type of test, $F(1,32)<1$, $n s$, but did reveal a significant interaction between learning condition and type of test, $F(1,32)=6.790, M S E=.42, p<.05$, $f^{2}=0.25$, indicating that participants who had learned individually exhibited more efficient retention performance, and participants who had learned in a group exhibited more efficient transfer performance. The interaction is depicted in Figure 1.

\section{****INSERT FIGURE 1 ABOUT HERE****}

With regard to mental effort, an ANOVA revealed a significant main effect of test performance $F(1,32)=52.02, M S E=.48, p<.001, f^{2}=0.68$, indicating that retention problems caused a lower mental effort than transfer problems. With regard to test performance, there was a main effect for type of test $F(1,32)=90.41, M S E=.03, p<.001, f=1.32$, indicating that learners performed better on the retention tests than on the transfer test. For learning condition, no significant results were found $F(1,32)<1$, ns. The learning condition x test-type interaction approached significance $\left(F(1,32)=4.10, M S E=.027, p=.052, f^{2}=1.32\right)$, suggesting that participants who learned individually performed better on retention problems, while participants who learned in a group performed better on transfer problems. The ANOVA performed on the time on task revealed neither significant main effects $(F(1,32)<1, n s)$ nor an interaction $(F(1,22)<1, n s)$

\section{Discussion}

In this study, it was hypothesized that group members would be able to collaborate with each other in a way that the cognitive load imposed by a complex task would be reduced. Due to 
this reduction, group members were expected to develop higher quality schemata than individual learners carrying out the same task. Consequently, it was predicted that group members would have to invest less mental effort to apply acquired knowledge and skills to tasks that differ from the ones trained, as indicated by more efficient transfer performance. In contrast, it was expected that learners carrying out the same complex tasks individually would not have the advantage of the collective workspace and thus would have less WM-capacity left to work with the interrelated information elements. This means that they were expected to be able to only focus on what is initially necessary to work with the elements (i.e., remembering them) and consequently would have to invest less mental effort remembering the information elements, as indicated by more efficient performance on a retention task.

This interaction hypothesis was confirmed. While those learning individually performed more efficiently on a retention task in the test phase than learners who had learned in a group, group learners performed more efficiently on transfer tasks than did individual learners. In other words, by making use of each others processing capacity through sharing the cognitive load imposed by the task, it was possible for group members to more deeply process the information elements and work with them by relating them to each other, and construct higher quality schemata in their long term memory. For individual learners who could only rely on their own WM and, thus, had to process all of the information elements themselves, the experienced mental effort in the learning phase was significantly higher than that of the group members. The limited processing capacity of the individual combined with the complexity of the learning tasks meant that it was only possible for them to focus on remembering the information elements instead of relating them to each other so as to construct higher quality schemata. The conclusion here is 
clear, namely that collaborative learning can have a positive effect on deep learning of complex cognitive tasks.

A second conclusion, based on the significantly lower metal effort scores of the group members during the learning phase and their more efficient performance on the transfer tasks during the test phase, is that the transaction costs caused by communication and coordination in the groups were not excessively high. For groups, excessive transaction costs could annul the benefit of the possibility of groups to divide the cognitive load among its members.

It should be noted that the learning conditions in this study can be considered rather artificial, for example, as a result of the very strict division of information and roles within groups and the fact that learners were not allowed to use pen and paper. In that sense, it is not clear to what extent the present results can be generalized to a real classroom setting. It can be assumed that the complex pattern of interactions between cognitive, motivational, and social factors that characterize such a real life context would add a lot of 'noise' to the data and cause the effects to be less pronounced than in this experimental study. We acknowledge that, ultimately, the research on group-based learning requires an interrelated perspective integrating cognitive, motivational, and social aspects. However, to be able to disentangle the contributions of each of these factors to the learning processes and outcomes of group-based learning, they need to be studied within tightly constrained experimental environments, one at a time, keeping all other aspects constant.

Although we have shown that learning-task complexity is an important factor that helps determine the effectiveness of group learning, it should be clear that it is not merely complexity of the tasks that determines if group learning, other than individual learning, is favorable in a certain context. Recent research has identified a number of other task characteristics relevant 
when considering group learning as a good option. This would, for example, be the case when positive cognitive conflict is necessary or desirable when solving a problem or creating a product, as is the case in argumentative learning (Munneke et al., 2007), when diversity in expertise or a multidisciplinary approach is necessary for carrying out a task or solving a problem (Kirschner et al., 2008), or when specific cognitive or metacognitive skills (e.g., reflection: King, 2007) or socio-cognitive skills (e.g., negotiation: Beers et al., 2007 or debating: Leitão, 2000; Veerman, Andriessen, \& Kanselaar, 2000) are the required processes in and/or products of learning.

In this study, the type of communication and coordination activities and communication that took place within the groups was not recorded or analyzed. Therefore, we do not know what topics were discussed, whether the discussions that were carried out were mostly content related, whether social talk was part of those discussions and, if so, to what extent, whether learners actually engaged in discussions at all, or whether every group member participated in the communication and coordination equally or whether there were roles or patterns of communication. We concentrated here on the transaction costs that would be detrimental for learning and therefore cause extraneous cognitive load. It could, however, also be possible that the communication among the group members was such that it fostered learning instead of hampered it and by doing so caused germane cognitive load (which is, in contrast to extraneous load, effective for learning). Carrying out such an analysis would add a useful and interesting new dimension to this study and would be interesting to analyze in further studies.

Another interesting topic for further research is determining how to measure a group's cognitive load. In this study, group load was considered to be the average of the individual mental-effort scores. However, group cognitive load could also be defined as the sum of the 
individual scores (i.e., the nominal score), in which case group cognitive load will be higher than an individual's cognitive load and a scale would need to be developed to determine what a relatively high and low group cognitive load is and how this could be compared to an individual cognitive load score, Another way of defining group cognitive load would be to ask the group as a whole to score their group mental effort on the 9-point rating scale that is also used for individuals. This way the experienced mental effort of the individual group members is lost, but the 9-point rating scale can still be used and because of this a comparison to an individual score is still possible. It might even be the case that it could be better to use two rating scales, one that measures the mental effort a group member experiences while solving a problem (the rating scale used in this experiment; Paas, 1992), and another that measures how much effort it took the group member to be a member of the group as a whole. These scores could be combined (e.g., either averaged or summed) to give an indication of the experienced cognitive load on two subjects, namely task complexity and transaction costs.

Finally, further research could be carried out to determine at which level of task complexity it becomes more effective and/or efficient to assign learning tasks to groups rather than to individuals. In such research, the optimal trade-off between task complexity, learner characteristics (e.g., expertise, age) and group characteristics (i.e., group size, group homogeneity with respect to learner characteristics) for the effectiveness of collaborative learning environments could be determined. We often see in both research and education that learners involved in collaborative learning or problem solving are required to send a minimal number of emails to each other or to add a minimal number of messages to a discussion board when working collaboratively via computer mediated communication (i.e., computer-supported collaborative learning). These requirements could be due to the fact that the learning tasks that 
the learners must carry out or the problems that the learners collaboratively must solve are not sufficiently complex to warrant the requested or required collaboration.

In summary, this study showed that group learning is superior to individual learning of a complex cognitive task if the transaction costs are kept to a minimum and if performance is measured on transfer problems. In contrast, individual learning is superior to group learning if performance is measured on retention problems. 


\section{References}

Andersson, J., \& Rönnberg, J. (1995). Recall suffers from collaboration: Joint recall effects of friendship and task complexity. Applied Cognitive Psychology, 9, 199-211.

Barron, B. (2003). When smart groups fail. The Journal of the Learning Sciences, 12(3), 307359.

Beers, P. J. (2005). Negotiating common ground: Tools for multidisciplinary teams. Unpublished doctoral dissertation, Open University of The Netherlands, Heerlen, The Netherlands.

Beers, P. J., Boshuizen, H. P. A., \& Kirschner, P. A. (2007). The analysis of negotiation of common ground in CSCL. Learning and Instruction, 17, 427-435.

Bernard, R. M., \& Lundgren-Cayrol, K. (2001). Computer conferencing: An environment for collaborative project-based learning in distance education. Educational Research and Evaluation, 7, 241-261.

Buchs, C., Butera, F., \& Mugny, G. (2004). Resource interdependence, student interactions and performance in cooperative learning. Educational Psychology, 24, 291-314.

Campion, M. A., Medsker, G. J. \& Higgs, A. C. (1993) Relations between work group characteristics and effectiveness: Implications for designing effective work groups. Personnel Psychology, 46, 823-850.

Ciborra, C., \& Olson, M. H. (1988). Encountering electronic work groups: A transaction costs perspective. In Proceedings of the 1988 ACM Conference on Computer-Supported Cooperative Work, Portland, Oregon, US. Available at http://doi.acm.org/10.1145/62266.62274

Cohen, J. (1988). Statistical power analysis for the behavioral sciences ( $2^{\text {nd }}$ ed.). Hillsdale, NJ: Lawrence Erlbaum. 
Cowan, N. (2001). The magical number 4 in short-term memory: A reconsideration of metal storage capacity. Behavioral and Brain Sciences, 24, 87-114.

De Westelinck, K., Valcke, M., De Craene, B., \& Kirschner, P. A. (2005). Multimedia learning in social sciences: Limitations of external graphical representations. Computers in Human Behavior, 21, 555-573.

Dillenbourg, P. (2002). Over-scripting CSCL: The risks of blending collaborative learning with instructional design. In P. Kirschner (Ed.), Three worlds of CSCL: Can we support CSCL? (pp. 61-91). Heerlen, The Netherlands: Open University of the Netherlands.

Dourish, P., \& Bellotti, V. (1992). Awareness and coordination in shared workspaces. In M. Mantel, \& R. Baecker (Eds.), Proceedings of the 1992 ACM conference on Computersupported cooperative work (pp. 107-114). New York, ACM Press.

Ellis, C. A., Gibbs, S. J., \& Rein, G. L. (1991). Groupware: Some issues and experiences. Communications of the ACM, 34, 38-58.

Fischer, F., Bruhn, J., Gräsel, C., \& Mandl, H. (1999, April). Mapping-enhanced collaborative knowledge construction. Paper presented at the Annual Meeting of the American Educational Research Association, Montreal, Quebec, Canada.

Fischer, F., Bruhn, J., Gräsel, C., \& Mandl, H. (2002). Fostering collaborative knowledge construction with visualization tools. Learning and Instruction, 12, 213-232.

Gregor, S. D., \& Cuskelly, E. F. (1994). Computer mediated communication in distance education. Journal of Computer Assisted Learning, 10, 168-181.

Gutwin, C. (1997). Workspace awareness in real-time distributed groupware. Unpublished doctoral dissertation. University of Calgary, Canada. 
Hallet, K., \& Cummings, J. (1997). The virtual classroom as authentic experience: Collaborative, problem-based learning in a WWW environment. In Proceedings of the annual conference on Distance teaching and learning: Competition-connection-collaboration (pp. 103-107). Madison, WI: University of Wisconson-Madison.

Heath, E. F. (1998). Two cheers and a pint of worry: An on-line course in political and social philosophy. Journal of Asynchronous Learning Networks, 2, 15-33.

Hiltz, S. R. (1998, November). Collaborative learning in asynchronous learning networks: Building learning communities. Invited Address at WEB98, Orlando, Florida [Online]. Retrieved November 11, 2003 from http://eies.njit.edu/ hiltz/collaborative_learning_in_asynch.htm.

Hobaugh, C. F. (1997). Interactive strategies for collaborative learning. In Proceedings of the annual conference on Distance teaching and learning: Competition-connectioncollaboration (pp. 121-125). Madison, WI: University of Wisconsin-Madison.

Hughes, C., \& Hewson, L. (1998). Online interactions: Developing a neglected aspect of the virtual classroom. Educational Technology 38, 48-55.

Johnson, D. W., Johnson, R. T. \& Stanne M. B (2001). Impact of goal and resource interdependence on problem-solving success. The Journal of Social Psychology, 129, 621-629.

Johnston, C. G., James, R. H., Lye, J. N., \& McDonald, I. M. (2000). An evaluation of collaborative problem solving for learning economics. Journal of Economic Education $31,13-29$.

Kester, L., \& Paas, F. (2005). Instructional interventions to enhance collaboration in powerful learning environments. Computers in Human Behavior, 21, 689-696. 
Individual and Group-Based Learning 30

King, A. (2007). Scripting collaborative learning processes: A cognitive perspective. In F. Fischer, K. Ingo, H. Mandl, \& J. M. Haake (Eds.), Scripting computer-supported collaborative learning : Cognitive, computational and educational perspectives. (pp. 1437). New York: Springer.

Kirschner, P. A., Beers. P. J., Boshuizen, H. P. A., \& Gijselaers, W. H. (2008). Coercing shared knowledge in collaborative learning environments. Computers in Human Behavior, 24, 403-420.

Kirschner, P. A., Sweller, J., \& Clark, R. E. (2006). Why minimal guidance during instruction does not work: An analysis of the failure of constructivist, discovery, problem-based, experiential, and inquiry-based teaching. Educational Psychologist, 46, 75-86.

Kollar, I., Fischer, F., \& Hesse, F. W. (2006). Collaboration scripts: A conceptual analysis. Educational Psychology Review, 18, 159-185.

Langfred, C. (2000). Work-group design and autonomy: A field study of the interaction between task interdependence and group autonomy. Small Group Research, 31, 54-70.

Laughlin, P. R., Bonner, B. L., \& Miner, A. G. (2002). Groups perform better than the best individuals on letters-to-numbers problems. Organizational Behavior and Human Decision Processes, 88, 605-620.

Laughlin, P. R., Hatch, E. C., Silver, J. S., \& Boh, L. (2006) Groups perform better than the best individuals on letters-to-numbers problems: Effects of group size. Journal of Personality and Social Psychology, 90, 644-651.

Leitão, S. (2000). The potential of argument in knowledge building. Human Development, 43, $332-360$. 
Littleton, K., \& Häkkinen, P. (1999). Learning together: Understanding the process of computer based collaborative learning. In P. Dillenbourg (Ed.), Collaborative learning: Cognitive and computational approaches (pp. 20-30). Amsterdam, The Netherlands: Pergamon.

Mäkitalo, K., Weinberger, A., Häkkinen, P., Järvelä, S., \& Fischer, F. (2005). Epistemic cooperation scripts in online learning environments: Fostering learning by reducing uncertainty in discourse? Computers in Human Behavior, 21, 603-622.

Malone, T. W., \& Crowston, K. (1990). What is coordination theory and how can it help design cooperative work systems? In F. Halasz (Ed.), Proceedings of the 1990 ACM conference on Computer-supported cooperative work (pp. 375 - 370). New York: ACM.

Mason, R. (1991). Analyzing computer conferencing interactions. International Journal of Adult Education and Training, 2, 161-173.

Mercer, N. (1996). The quality of talk in children's collaborative activity in the classroom. Learning and Instruction, 6, 359-377.

Meudell, P. R., Hitch, G. J., \& Kirby, P. (1992). Are two heads better than one? Experimental investigations of the social facilitation of memory. Applied Cognitive Psychology, 6, 525543.

Morgan, R. L., Whorton, J. E., \& Gunsalus, C. (2000). A comparison of short-term and long-term retention: Lecture combined with discussion versus cooperative learning. Journal of Instructional Psychology, 27, 53-58.

Munneke, L., Andriessen, J., Kanselaar, G., \& Kirschner, P. A. (2007). Supporting interactive argumentation: influence of representational tools on discussing a wicked problem. Computers in Human Behavior, 23, 1072-1088. 
Individual and Group-Based Learning 32

Ortiz, A. E., Johnson, D. W., \& Johnson, R. T. (1996). The effect of positive goal and resource interdependence on individual performance. The Journal of Social Psychology, 136, 243249.

Paas, F. (1992). Training strategies for attaining transfer of problem-solving skill in statistics: A cognitive load approach. Journal of Educational Psychology, 84, 429-434.

Paas, F., Renkl, A., \& Sweller, J. (2003). Cognitive load theory and instructional design: Recent developments. Educational Psychologist, 38, 1-4.

Paas, F., Renkl, A., \& Sweller, J. (2004). Cognitive load theory: instructional implications of the interaction between information structures and cognitive architecture. Instructional Science, 32, 1-8.

Paas, F., Tuovinen, J. E., Tabbers, H., \& Van Gerven, P. W. M. (2003). Cognitive load measurement as a means to advance cognitive load theory. Educational Psychologist, 38, 63-71.

Paas, F., \& Van Merriënboer, J. J. G. (1993). The efficiency of instructional conditions: an approach to combine mental effort and performance measures. Human Factors, 35, 737743.

Paas, F., \& Van Merriënboer, J. J. G. (1994b). Instructional control of cognitive load in the training of complex cognitive tasks. Educational Psychology Review, 6, 351-372.

Salas, E., Sims, D., \& Burke, C. (2005). Is there a 'Big Five' in teamwork? Small Group Research, 36, 555-599.

Savery, J. R., \& Duffy, T. M. (1995). Problem based learning: An instructional model and its constructivistic framework. Educational Technology, 35, 31-38. 
Slavin, R. E. (1983). When does cooperative learning increase student achievement? Psychological Bulletin, 94, 429-445.

Slavin, R. E. (1995). When and why does cooperative learning increase achievement? Theoretical and empirical perspectives. In R. Hertz-Lazarowitz \& N. Miller (Eds.), Interaction in cooperative groups: The theoretical anatomy of group learning (pp. 145173). New York: Cambridge University Press.

Sloffer, S. J., Dueber, B., \& Duffy, T. M. (1999). Using asynchronous conferencing to promote critical Thinking: Two implementations in higher education (CRLT Technical report no. 8-99). Bloomington, IN: Indiana University.

Soller, A. L. (2001). Supporting Social Interaction in an Intelligent Collaborative Learning System. International Journal of Artificial Intelligence in Education, 12, 40-62.

Sweller, J. (1988). Cognitive load during problem-solving: Effects on learning. Cognitive Science, 12, 257-285.

Sweller, J., Kirschner, P. A., \& Clark, R. E. (2007). Why minimal guidance during instruction does not work: A reply to commentaries. Educational Psychologist, 47, 115-121

Sweller, J., \& Sweller S. (2006). Natural information processing systems. Evolutionary Psychology, 4, 434-458.

Sweller, J., Van Merriënboer, J. J. G., \& Paas, F. (1998). Cognitive architecture and instructional design. Educational Psychology Review, 10, 251-295.

Taha, L. H., \& Caldwell, B. S. (1993). Social isolation and integration in electronic environments. Behaviour \& Information Technology 12, 276-283.

Tuovinen, J. E., \& Paas, F. (2004). Exploring multidimensional approaches to the efficiency of instructional conditions. Instructional Science, 32, 133-152. 
Van Boxtel, C. A. M., Van der Linden, J., \& Kanselaar, G. (2000). Collaborative learning tasks and the elaboration of conceptual knowledge. Learning and Instruction, 10, 311-330.

Van Bruggen, J., Kirschner, P. A., \& Jochems, W. (2002). External representation of argumentation in CSCL and the management of cognitive load. Learning and Instruction, $12,121-138$.

Van den Bossche, P., Gijselaers, W., Segers, M., \& Kirschner, P. (2006). Social and cognitive factors driving teamwork in collaborative learning environments. Small Group Research, $37,490-521$.

Van Drie, J., Van Boxtel, C. A. M., Jaspers, J., \& Kanselaar, G. (2005). Effects of representational guidance on domain specific reasoning in CSCL. Computers in Human Behavior, 21, 575-602.

Van Gog, T., \& Paas, F. (2008). Instructional efficiency: Revisiting the original construct in educational research. Educational Psychologist, 43, 16-26.

Veerman, A. (2000). Computer-supported collaborative learning through argumentation. Unpublished doctoral dissertation, Utrecht University, Utrecht, The Netherlands.

Veerman, A. L., Andriessen, J. E. B. \& Kanselaar, G. (2000). Learning through synchronous electronic discussion. Computers \& Education, 34, 269-290.

Veerman, A., \& Veldhuis-Diermanse, E. (2001). Collaborative learning through computer mediated communication in academic education. In P. Dillenbourg, A. Eurelings, \& K. Hakkarainen (Eds.), European perspectives on computer-supported collaborative learning (pp. 625-632). Maastricht, The Netherlands: University of Maastricht. Wageman, R. (1995). Interdependence and group effectiveness. Administrative Science Quarterly, 40, 145-180. 
Webb, N. M., \& Palincsar, A. S. (1996). Group processes in the classroom. In D. C. Berliner \& R. C. Calfee (Eds.), Handbook of educational psychology (pp. 841-873). New York: Macmillan.

Weigel, V. B. (2002). Deep learning for a digital age: Technology's untapped potential to enrich higher education. San Francisco, CA: Jossey-Bass

Weldon, M. S., \& Bellinger, K. D. (1997). Collective memory: Collaborative and individual processes in remembering. Journal of experimental psychology: Learning, memory, and cognition, 23, 1160-1175.

Whyte, G. (1991). Decision failures: why they occur and how to prevent them. Academy of Management Executive, 5(3), 23-31.

Yamane, D. (1996). Collaboration and its discontents: Steps toward overcoming barriers to successful group projects. Teaching Sociology, 24, 378-383. 
Table 1

Means and Standard Deviations of the Dependent Variables in the Training and Test Phase:

Performance (0-1),, Mental Effort (1-9), Retention Efficiency (based on z-scores of Mental Effort

and Performance), Transfer Efficiency (based on z-scores of Mental Effort and Performance), and Time (sec.)

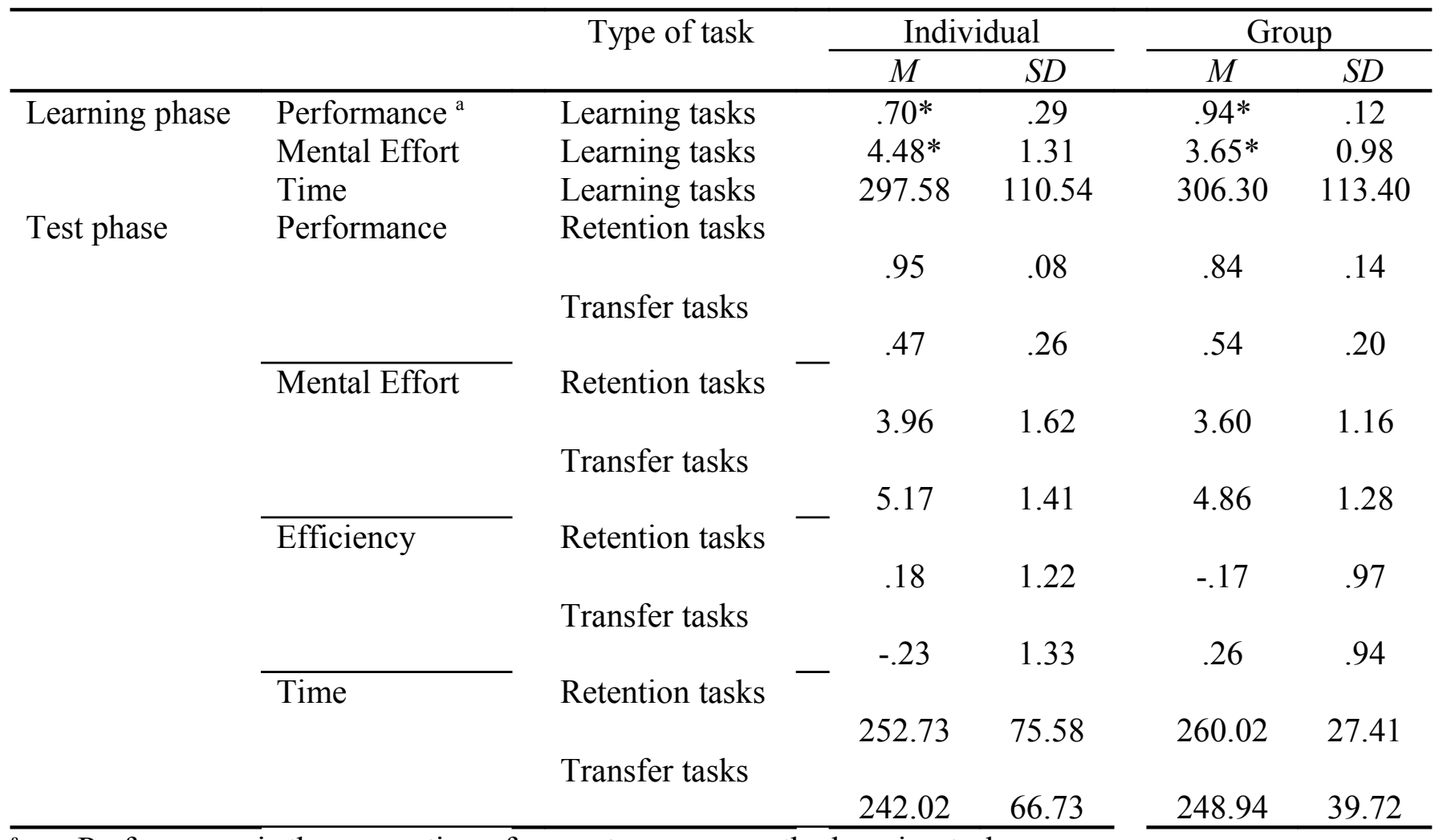

a Performance is the proportion of correct answers on the learning tasks.

$* \quad p<.05$ 
Individual and Group-Based Learning 37

Figure Caption

Figure 1. Interaction between type of learning condition and type of test. 
Individual and Group-Based Learning 38

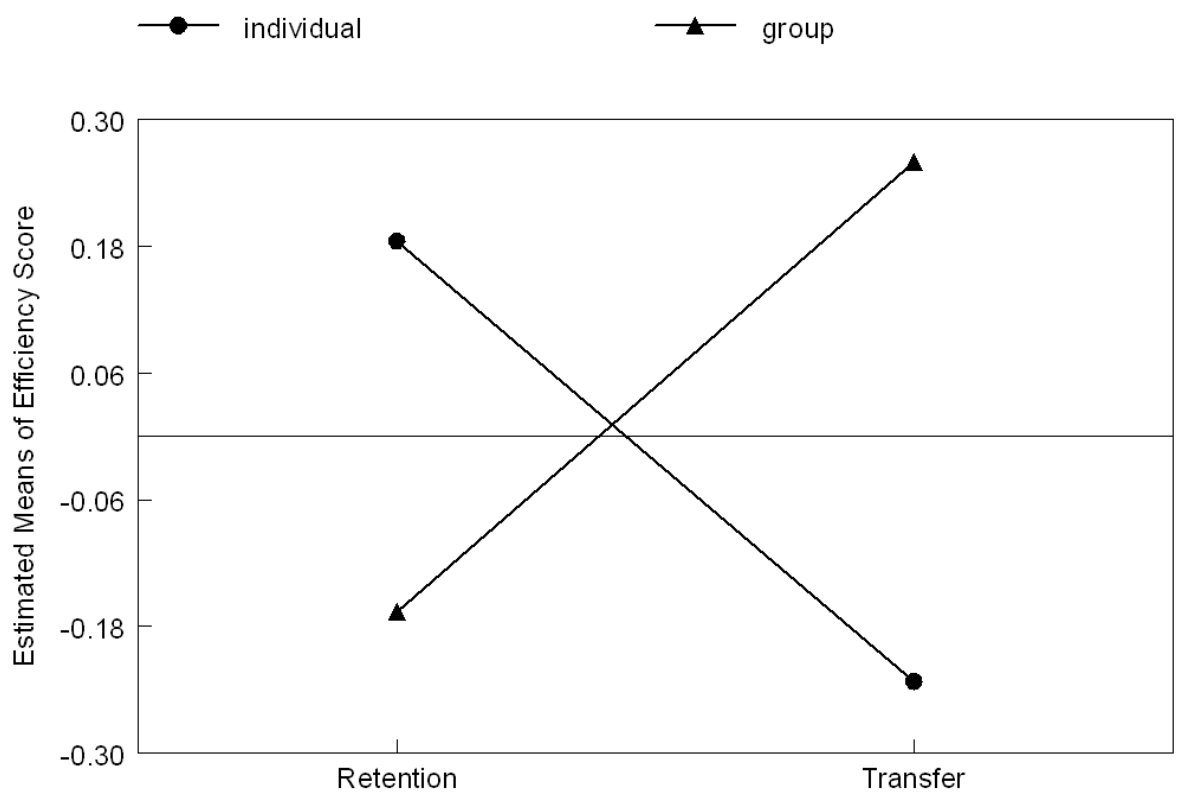

